\title{
VIOLENCIA INVISIBLE O DEL ÉXTASIS AL DOLOR.
}

\author{
Lourdes Fernández Rius'. \\ "hay amores que matan" \\ "quien bien te quiere te hará llorar" \\ "mátame pero no me dejes nunca jamás" \\ "quiero un hombre violento" \\ "sin ti es inútil vivir" \\ "en la cárcel de tu piel" 2
}

Las relaciones de pareja se asocian con fantasías de éxtasis y amor. Sin embargo, la pareja no solamente es ternura. Dicho idilio es acosado constantemente por vivencias de servidumbre y dominio, por contradicciones, crisis, encantos - desencantos, encuentros - desencuentros, desembocando en pequeñas y grandes rebeliones.

¿Cuándo el amor, el erotismo y la sexualidad dejan de ser éxtasis para convertirse en dolor?

¿Qué significación posee en ello la perpetuidad de la cultura patriarcal?

¿Cuáles representaciones de lo femenino y lo masculino transitan aún en la subjetividad de algunas mujeres y hombres?

Hoy no es posible minimizar el progreso dentro del cual el patriarcado de coerción deja su lugar detrás. En los últimos años las mujeres de muchos países han logrado un reconocimiento como ciudadanas y la ampliación significativa de sus derechos. Se han desmontado las barreras que hasta hace poco les impedía acceder a niveles más elevados de formación o a ciertos puestos de trabajo o de dirección, aunque en realidad no se haya logrado una redistribución completamente justa de los recursos ni del poder, incluso en los países más favorables a la equidad.

Ahora, sutil, consensual, con otros rostros de dominación, el patriarcado - universal y longevo - está aún aquí, impenitente. Los valores y normas identificables con una determinada construcción simbólica de masculinidad y feminidad sobreviven aunque ello apunte hacia un sincretismo en el cual se vertebran diversidad de culturas, costumbres, tradiciones, religiones, relaciones económicas y núcleos de género.

Estamos ante un tránsito en el cual coexiste lo tradicional y lo innovador

Facultad de Psicología. Universidad de La Habana, Cuba. E-mail: Lourdesf@psico.uh.cu.

2 Fragmentos de canciones populares. 
en puntos de tensión entre conservación y cambio.

Aunque se pulsa por desmontarla y redimensionarla, no ha desaparecido la noción de lo femenino asociada al hecho de engendrar y parir, a lo que es dado por la naturaleza seguida de una maternidad sacrificial. Ello articula con la idea de sexo - procreación a la vez que deslegitima la sexualidad - placer en un cuerpo que por demás es objeto de deseo. Dulzura, delicadeza, sentimientos, intuición: ¿lo femenino?

Las mujeres, quienes predominantemente son objeto de tales asignaciones, se ven atrapadas en el cumplimiento del "mandato cultural": ser "madresposas - amas de casa", líderes y pilares emocionales de una familia, en fin, el cuidado. Las mujeres son seres para y a través de los demás. (Lagarde, M. 2001) Esto obstaculiza su autonomía y su condición de sujetos tendiendo a ser dependientes económica, social, jurídica y afectivamente.

Se enlazan aquí tres mitos: ser mujer = ser madre, la erótica femenina es pasiva y vivir en pareja es el centro de sus vidas.

¿Cómo vivir todos estos mandatos? ¿Cómo lograr que nuestro cuerpo siempre sea deseado y a la vez tener que reprimirlo en el espacio del deseo porque no es lo mismo "estar buena" que "ser buena"?. Se puede "estar buena" reprimiendo el cuerpo deseante ofreciéndolo para dar vida y cuidado, a la vez que se pierde vida y autocuidado a cambio, de "ser buena".

Asimismo, en medio de la permeabilidad de las fronteras de género subsiste una noción de lo masculino articulada alrededor de la virilidad, la potencia, del sexo como placer, de la homofobia. Los estereotipos van cambiando, pero la masculinidad, en su connotación patriarcal, sobrevive, permitiendo incentivar ciertos comportamientos de los varones y de algunas mujeres.

Perfección, excelencia, razón, competencia, dominio, agresión, autonomía, independencia, decisión, autosuficiencia, seguridad emocional, control sentimental: ¿lo masculino?

Este contenido se asigna de modo predominante a los hombres, quienes conforman su identidad de género, en buena medida, alrededor de los genitales asociados inconscientemente con la idea de poder de ahí las frases o palabras que hacen referencia a estos para subrayar fuerza, ímpetu, decisión, dominación. El fantasma de la homosexualidad les compulsa hacia la "hipervirilidad" insistente como son los alardes de proezas eróticas muchas veces distorsionadas, fantaseadas y hasta inventadas para autoafirmarse ante sí y sus pares, la exageración de la agresividad o la censura en la expresión de la ternura.

Para añadir y acentuar - y radica en ello la idea central que deseo enfatizar - los valores y roles escindidos para cada género, apoyándose en las diferencias sexuales, derivan en desigualdad en la medida en que se articulan a una jerarquía, asimetría y poder de lo masculino sobre lo femenino. Unas veces visibles y otras ocultas. Estamos ante el poder patriarcal, pieza bien antigua que sostiene hasta hoy buena parte de la injusticia y desigualdades humanas y que constituye la esencia de la violencia en la vida amorosa y familiar.

Poder entendido como la posibilidad de control y dominio sobre la vida 
o actividades de otras personas, básicamente para lograr obediencia y sus derivaciones. Supone tener recursos como bienes o afectos que aquella persona que se quiera controlar valore y no posea así como medios para sancionar y premiar a quien obedece.

El control o poder puede ejercerse sobre cualquier aspecto de la autonomía de la persona a la que se busca subordinar (pensamiento, sexualidad, economía, capacidad decisoria, afectos, disponibilidad de tiempo, posibilidades de desarrollo personal, etcétera).

Son varias las manifestaciones que indican la continuidad del poder patriarcal. Una de ellas es el feminicidio y la elevada incidencia de violencia extrema en virtud de lo cual decenas de mujeres perecen diariamente en diversos países. La desigualdad de género está fuertemente relacionada con el analfabetismo, la inequidad en el acceso a la educación y con la pobreza humana. Por ejemplo, las tecnologías educativas no son alcanzadas por la mayoría de las mujeres, 60 millones de niñas no llegan a la enseñanza primaria y dos tercios de los 960 millones de analfabetos son mujeres (Sedeño, 1999)

Persiste la división sexual del trabajo, en un mercado laboral que le es desfavorable a las mujeres a partir de salarios más bajos y de empleos menos prestigiosos o bloqueados en cuanto al ascenso en calificación o en puestos de toma de decisiones.

Otra es la doble o triple jornada laboral derivada de la falta de consideración del trabajo doméstico y familiar no remunerado que hacen las mujeres "por amor" y que supone una sustracción añadida de energía física, psíquica y de tiempo de vida en detrimento del desarrollo personal de las mismas.

El tiempo de las mujeres aparece como algo gratuito, infinito, no considerado en muchos países por las políticas sociales y económicas ni en la dinámica interna de la vida familiar.

Sin embargo, deseo detenerme en otra evidencia de continuidad del poder patriarcal tal vez menos explícita. Se trata de la explotación de la condición de género de las mujeres, del amor, el afecto y el cuidado ofrecido por ellas en el marco de las relaciones de pareja y filiales.

Es justo la esfera de la sexualidad, del erotismo, de los afectos, de los vínculos amorosos, del cuidado donde con más facilidad se perpetúa, "imperceptiblemente", de modo inconsciente y acrítico, la relación de dominio sumisión patriarcal y la sujeción femenina. Esto constituye un punto nodal en la comprensión de las relaciones de género actuales. Me empeñaré en develar algunas de sus aristas.

Este poder, arraigado como idea y como práctica en nuestra cultura, se perpetúa por su naturalización. Deriva de aquí un sistema de dominio - sumisión en lo económico y en lo social que se expresa psicológicamente en las relaciones de pareja y familiares desde un modo sutil hasta modos más evidentes y explícitamente violentos.

La pareja es un espacio particular de poder. En esta se desarrollan aspiraciones personales, sexuales, de trabajo, de creación y la vida cotidiana. Por ello, cada cual intentará ejercer influencia sobre la vida de la otra persona, controlar, intervenir, prohibir, decidir, defenderse, cobrar deudas, vengarse y 
hacer justicia.

En las relaciones de pareja estas situaciones de poder son más desfavorables a las mujeres y suelen ser invisibilizadas para acentuar la creencia de que hoy en día en la vida amorosa se desarrollan prácticas recíprocamente igualitarias. Por otra parte, este tema del poder en los vínculos amorosos se vive como enfrentamientos pragmáticos, como molestias menores, como asuntos de "marido y mujer donde nadie se debe meter", sin la conciencia del poder que se está ejerciendo o recibiendo.

La violencia de género es entendida como cualquier acto, omisión, amenaza o control que se ejerza contra las mujeres en cualquier esfera, que pueda resultar en daño físico, emocional, sexual, intelectual o patrimonial con el propósito de intimidarlas, castigarlas, humillarlas, mantenerlas subordinadas, negarles su dignidad humana, el derecho a decidir sobre su sexualidad y su integridad física, mental o moral, menoscabar su seguridad como persona, respeto por sí misma o disminuir sus capacidades físicas o mentales (Guzmán, 1994).

La violencia psicológica se torna invisible, queda enmarcada dentro una familiaridad acrítica por lo cual se reproduce fácilmente a través de la cultura. Su desmontaje resulta más difícil y aparece mucho más extendida y habitual de lo que pudiéramos imaginar.

La violencia psicológica se aprecia en la lucha por el poder, la competencia por la influencia o dominio que alguien puede ejercer sobre otra persona. En algunas parejas esta lucha por el poder se hace de modo sutil y hasta elegante. En otras parejas unos ejercen dominio en una esfera de la vida y otros, en otras esferas.

Volvamos puntualmente ahora sobre una de las caras de la moneda: la noción patriarcal de feminidad. Si examinamos detenidamente dicha noción podremos identificar diversos elementos alrededor de los cuales puede tejerse la violencia de género en el espacio de los vínculos amorosos.

El cuerpo de la mujer como objeto de deseo. La autoimagen corporal sigue ocupando un lugar esencial en los procesos de autoconciencia, de identidad personal y autovalorativos en las mujeres y se manifiesta de modo especial en la vida sexual y amorosa.

\section{"Después de parir ha cambiado mi cuerpo... ahora hay muchachas mucho más lindas... Yo no me siento digna de él. Yo me siento inferior". ${ }^{3}$}

El cuerpo, la belleza, el tiempo, la edad, la salud, son ejes vitales en la articulación de la identidad femenina. Esto es uno de los factores generadores de violencia hacia las mujeres en lo que se conoce como la "tiranía del cuerpo"

\footnotetext{
Estos fragmentos en negrita y cursiva que a aparecerán en lo adelante se corresponden con testimonios de mujeres que solicitan orientación psicológica en el Programa de Orientación para la Vida Amorosa y de Pareja en el Centro de Orientación Psicológica de la Facultad de Psicología de la Universidad de La Habana.
} 
(Lagarde, M. 2001). Una sexualidad erótica y reproductora en un cuerpo para otras personas o servidumbre erótica de las mujeres.

A su vez, las mujeres son partícipes y viven este interjuego de deseo y ser deseada como criterio de autoestima y amor propio.

La feminidad que se espera de las mujeres las compulsa a vivir la sexualidad más para la procreación que para el placer lo cual subsiste hoy a pesar de los discursos innovadores de libertad y modernidad según los contextos específicos.

\section{"las mujeres no debemos expresar nuestros deseos sexuales, esto me parece que es como ser prostituta".}

Esto es una violencia desde la cultura que impone restricciones e impide el pleno desarrollo personal de las mujeres. El placer sexual, aparece aquí asociado al pecado, a lo desagradable, a lo penalizado, provoca culpas, miedo, castigo y autocastigo. En este sentido, no menos importante es el vínculo más o menos inconsciente que muchas mujeres hacen entre la genitalidad masculina y el poder:

\section{"que no se aprovechen de ti", "todos los hombres quieren lo mismo", "cuando logran lo que quieren te dejan".}

Como una presunción eterna de vulnerabilidad imaginada y a veces, lamentablemente, real. A ello las mujeres responden con rechazo lo cual subyace en no pocos de los problemas sexuales femeninos los cuales se vinculan al hecho de no permitirse dicho placer y se expresan en el temor hacia el autoerotismo o en el sentimiento de empoderamiento de la otra persona con respecto a sí mismas.

La construcción cultural del mito de la erótica "pasiva" en las mujeres, instala en ellas una heteronomía que sostiene la creencia de una única forma de placer, de la heterosexualidad exigida, de la familia monogámica, de la fidelidad femenina versus infidelidad masculina.

\section{"cuando conozco a un hombre e inicio relaciones sexuales finjo tener desconocimiento en materia de sexualidad".}

Algunas mujeres temen desafiar en el sexo, temen demostrar mucho conocimiento o emplear el conocimiento que se poseen, temen perder la aceptación de "buena mujer" en el sentido de la madresposa, lo cual resulta de especial importancia en la sexualidad e identidad de las mujeres.

Entran en oposición alimentando la dicotomía: madre - buena mujer versus prostituta - mala mujer. Integrar la madre y la mujer en una, solo es posible desde la sinonimia del mito "ser mujer = ser madre" que termina por negar a la mujer.

Así, la maternidad, eje aún de la identidad femenina para la mayoría de las mujeres, además de espacio de disfrute y realización personal, es también condición de presiones ocultas, vía sutil de control, de dominio, y en su connotación sacrificial, de autoanulación. Esto se expresa, entre otros aspectos, 
en la perpetua incompatibilidad entre lo privado y lo público que es vivida con culpas por las mujeres además de la incidencia que ello trae en sus posibilidades de desarrollo humano.

Muchas mujeres exitosas en espacios públicos, profesionales, están solas o no tienen hijos, como si el éxito estuviese asociado al sacrifico de la vida en familia.

Se expresa también cuando se culpa a las mujeres ante fallas en la educación de los hijos, en la atención y cuidado del hogar y la familia, cuando se prohíbe o interfiere en un nuevo vínculo amoroso de ellas: "mi hijo no tendrá padrastro" dice un señor a su ex - esposa. Esta es una de las formas de ejercer dominio y violencia psicológica, de someterlas y hacerlas desistir de sus proyectos personales.

Hijos, hijas, esposos, padres, familiares son fuente de culpas sobre todo cuando las mujeres deciden vivir sus propias vidas.

Asimismo, se observa en ocasiones el abuso de la capacidad femenina de cuidado como es fomentar o crear condiciones para que las mujeres prioricen sus conductas de cuidado incondicional en detrimento de sus espacios propios. El aniñamiento tiránico o la inspiración de lástima de algunos hombres o familiares incitan la "predisposición" femenina al cuidado y le inducen a pensar que sin ellas todo podría terminar muy mal.

En la cultura patriarcal suelen ser los hombres los dominantes y más violentos, para un comportamiento de dependencia y maternaje ampliado en las mujeres llegando algunas a tolerar durante años la hostilidad y la agresividad de sus parejas con el presunto mito de: "quien bien te quiere te hará Ilorar". El asunto se acrecienta cuando las mujeres no colocan límites a esta situación. Durante el proceso de socialización se va creando en las mujeres una dependencia emocional, una actitud de renuncia, entrega, subordinación y obediencia y algunas asisten con cierta naturalidad a la expropiación de su cuerpo, de su sexualidad y de su subjetividad.

Por lo general, las mujeres quedan en sujeción. Este es el contrato sexual que legitima la dominación en el ámbito privado aunque desde el contrato social se hable de mayor justicia y democracia. Se trata de una igualdad formal, de derechos, a la vez que una subordinación social, psicológica de las mujeres como "madresposas" en el marco de la cultura patriarcal, dentro o fuera del matrimonio.

Violencia de género evidente sostenida por la compulsión de cumplir el mandato cultural de vivir en pareja y la naturalización del comportamiento infiel de los hombres.

\section{"Aguanto todo esto por mantener el matrimonio pues pienso que no encontraría otro hombre, en fin... todos los hombres hacen lo mismo"}

Es frecuente observar la existencia de mujeres que se encuentran en momentos de crisis en sus vínculos amorosos en especial porque sus parejas les anuncian la separación o muestran indicadores de distanciamiento emocional o ellas intuyen que es posible que exista o se ha hecho real una infidelidad. La idea implícita es alcanzar fuerzas para "aguantar", "esperar", 
"resignarse" como si una sobrestimación del dolor adquiriera, inconscientemente, significados de afecto y autoestima. El prototipo de la mujer ideal sacrificada, abnegada, víctima.

La expresión: "mujeres que aman demasiado" se ha utilizado para caracterizar a las mujeres que persisten continuar con sus parejas aunque sean víctimas de maltrato psicológico o físico. En la relación de pareja típica, construida sobre la base de "cierta igualdad" se reedita, sin embargo, una desigualdad constante y es donde justamente las mujeres aman demasiado.

\section{"Voy a esperar a que a él se le pase esta situación", "es conveniente mantener el matrimonio... la vida es muy difícil para vivirla sola".}

Las mujeres son dueñas de su capacidad de amor que pueden dar libre y voluntariamente, no hay fuerzas formales hoy que puedan obligarlas. Pero hay otras fuerzas. Muchas mujeres - como tendencia - necesitan amar y ser amadas para habilitarse socio - existencialmente como personas. A la vez, carecen de autoridad para determinar las condiciones del amor y sus productos.

Tras décadas de igualdad legal, aún se fuerza a las mujeres a motivar su condición de complemento útil de los hombres. Se instituye el contrato sexual en virtud del cual las mujeres continúan su subordinación y que por producirse en el ámbito privado, aparece invisible e irrelevante.

Es este el ámbito de mayor dificultad para la autonomía femenina. Este es también el punto de lucha más difícil hoy desde una lógica feminista, pues justo en este ámbito se comprometen afectos, lealtades, ganancias emocionales a las que no siempre es fácil renunciar o afrontar.

Las relaciones desiguales de poder en detrimento de las mujeres afectan su autoestima y salud mental y las compulsan a la postergación de su persona en beneficio de los demás. De lo contrario - al no cumplir con el mandato cultural - es considerada como fracasada.

El impacto económico que posee la salida de las mujeres al trabajo remunerado y el cambio que supone para la familia la doble jornada femenina, constituyen uno de los puntos más traumáticos en las sociedades contemporáneas, pues se torna conflictiva la exigencia a los hombres de mayor participación en el ámbito privado.

\section{"espero de él que le ponga más interés a la casa, a la familia”}

La distribución de roles en el hogar así como la dinámica de interrelación íntimo psicológica en la vida privada, siguen siendo sexistas. Ello ha profundizado las condiciones para que la pareja y la familia se conviertan en el medio más efectivo para acentuar la violencia, el autoritarismo, la intolerancia y la explotación del trabajo de las mujeres. Así el intercambio desigual de cuidados y placeres es otra expresión de violencia de género.

En la forma de relación socio - sexual que domina actualmente, el amor de las mujeres es entregado libremente. Sin embargo, dada la jerarquía de género habrá un desequilibrio en el afecto entregado, pues en términos de 
cuidados las mujeres siempre entregarán más sin la debida retribución. Esto posibilita a otras personas, mantener su autoridad en la medida que este confort psicológico les permite realizarse en otros ámbitos. Esto se acompaña de disponer de tiempo libre a costa de la sobre utilización del tiempo de las mujeres.

Una novedad de las recientes décadas: la figura masculina deja de ser la proveedora por excelencia. La paridad en la contribución económica e incluso el hecho de que en ocasiones sean las mujeres quienes aporten más en este sentido, trastoca el modo en que tradicionalmente había sido diseñado el poder a lo interno de la vida en pareja y familiar.

Al hacerse las mujeres coprovidentes, la autoridad se comparte y se avanza en un proceso que hace tambalear las jerarquías e impone un movimiento hacia relaciones más democráticas y de colaboración lo cual se va alcanzando con fuertes tensiones.

Surge el "acuerdo contracultural" o cierta inversión de roles de género, lo cual, sin redimensión subjetiva, se convierte en fuente de desacuerdos, hostilidad mutua y en fuertes luchas por el poder, donde cada cual impone sus criterios y opiniones y cobra deudas desde su lugar tradicional que se conserva intacto aunque el acuerdo referido tenga un rostro innovador.

No son pocos los conflictos que se generan al interior de la pareja y la relación de ésta con su entorno cuando es la mujer la que posee mejor posición social, intelectual, laboral y aporta más económicamente a la vida familiar.

La contracultura y el desequilibrio que ocasiona en otra dirección, se cobran con una violencia sutil, emocional, en el terreno de los afectos, donde las mujeres, además de la sobrecarga laboral, emergen privadas de la arista más tradicional y casi intacta hasta hoy del rol femenino: la madresposa.

El seudo apoyo - para evitar la oposición frontal - sin ir acompañado de acciones cooperativas, es una forma de violencia realizada hacia mujeres que acrecientan su ingreso al espacio público. Retirar el afecto y tomar distancia, manifestar irritabilidad y crítica, ataques y culpas mediante quejas, reproches y descalificaciones, son alternativas hirientes muy típicas de parejas que hacen del vínculo una lucha por el poder y una batalla real.

En este contexto, las mujeres que creen obrar en libertad, están más bien obedeciendo a nuevas consignas sociales, ser todo al mismo tiempo: "madres asalariadas" con doble jornada, "monjas" en aporte de fuerza de trabajo a la colectividad y "sexy" para atraer a sus parejas, tal como promueven las revistas: la supermujer.

Esta multiplicidad de roles implica un constante desplazamiento por habilidades diferentes a la vez que gran costo en energía psicológica al tener que conciliar lógicas, sistemas de valores, modos de pensar, sentir y actuar muy distintos. La tensión se resuelve por medio de negociaciones en el mejor de los casos o se desplaza a través de padecimientos, malestares y agresiones, lo cual constituyen reediciones de violencia de género.

La efectividad de todas estas maniobras, junto a la naturalización del sometimiento y la falta de autoafirmación de algunas mujeres, forman una combinación: mujeres maltratadas muy deterioradas en su autonomía y varones violentos con aislamiento emocional progresivo y creciente desconfianza hacia mujeres que nunca terminan de someterse plenamente. 
Estas son las consecuencias de las asimétricas relaciones de género en muchos vínculos amorosos. Va quedando así para este espacio - de éxtasis, amor e "idilio" - intimidad dañada, un ejercicio de control más que de respeto y comprensión, privación de necesidades y ataques a la estima personal, incomunicación más que afrontamiento constructivo de las diferencias, a pesar de que algunos y algunas se conformen y satisfagan con la reproducción pasiva del rol.

No podemos afirmar rotundamente que hoy exista más violencia de género que hace décadas atrás. Lo que sí es cierto que se han creado condiciones para que la violencia se recrudezca, se extienda, se agudicen las tensiones de género y se incrementen de modo acentuado las mujeres cada vez más críticas y contestatarias ante la subordinación y ante situaciones de violencia en los vínculos amorosos.

Por otra parte, aunque este fenómeno va variando en la medida en que se acrecienta la autonomía intelectual, económica y sexual de las mujeres aún no se han producido suficientes cambios como para resolver completamente el sentimiento de dependencia emocional ni la adhesión a la feminidad tradicional. Tampoco se han producidos los suficientes cambios que alivien a la masculinidad de la persecución por la perfección, la represión afectiva y el ejercicio del poder.

Los cambios generados no están acompañados de una real y completa redimensión en los valores patriarcales ni en las propias mujeres, ni en los hombres, ni en la sociedad en su conjunto. Se mantienen los supuestos que sostienen el discurso educativo, científico, social y las prácticas educativas sexistas tradicionales.

La subsistencia de manifestaciones de degradación de la imagen femenina en los medios de comunicación, los materiales educativos, en los diversos discursos y mitos sociales, artísticos, publicitarios y en la literatura crean un contexto sociocultural de aceptación, tolerancia e impunidad sexista donde anida cómodamente la violencia que se observa en el ámbito de la pareja.

El viaje no se ha producido en sistema y más que un cambio por desmontaje y reconstrucción estamos ante un "cambio" por adición, que resulta necesario, pero no suficiente aún para lo que se desea y espera - en términos de avance en valores humanos - en las sociedades contemporáneas.

Relaciones equitativas y justas entre las personas atendiendo al género, requieren de cambios en lo económico, lo político, en el imaginario social. Incluye a lo individual, lo institucional y a quienes producen conocimiento y cultura.

Acciones de prevención, orientación y educación individual y grupal pueden estimular el impulso hacia nuevas feminidades y nuevas masculinidades que, aunque diferentes, no necesiten para legitimar sus diferencias, pensarse como desiguales en confrontación y exclusión. Ello contribuiría a desarticular las dicotomías.

Supone una resignificación de lo que hasta hoy se ha estado entendiendo por hombre - mujer, masculino - femenino, maternidad paternidad, familia. Es por ello que origina una revolución intelectual, cultural y en las relaciones sociales. 
Supone para las mujeres la recuperación de sus cuerpos para sí, de poder aceptarlos, vivirlos y disfrutarlos sin tiranías culturales y sin temores de vulneración. De recuperar una sexualidad - placer y la autonomía de decidir desde el cuerpo y la sexualidad las maneras deseadas para hacerlo vibrar, en pareja y no, para la procreación y no. De cuidar y autocuidarse. Supone para los hombres la recuperación de la capacidad de vivir en paridad y no en supremacía, de aceptar la posibilidad de la vulnerabilidad y la expresión emocional.

Diferencia - jerarquía - desigualdad - discriminación - violencia, circuito invisible en retroalimentación que la cultura reedita cotidianamente, para contradecir el más mínimo valor predicado desde una conciencia moral y humanista. Analizar detenidamente esto posee especial significación pues avanzar acciones de transformación social nos convoca a continuar, incesantemente, en el análisis crítico y en la elaboración de fundamentos y acciones que progresivamente tiendan a desmontar la cultura patriarcal hacia la construcción de sociedades y relaciones de pareja y familiares cada vez más humanas, diversas y democráticas.

\section{REFERENCIAS.}

BONINO, Luis. Micromachismos: La violencia invisible en la pareja en Hombres por la igualdad. www. Hombresigualdad.com (2004)

FERNÁNDEZ, Ana María Las mujeres en la imaginación colectiva. Buenos Aires, Paidós. (1993)

FERNÁNDEZ, Ana María. La mujer de la llusión. Buenos Aires, Paidós. (1993)

FERNÁNDEZ, Lourdes. Mujeres académicas: ¿Conflictos de roles? En Feminismos: del pasado al presente. España, Universidad de Salamanca. (2000)

FERNÁNDEZ, Lourdes. Género, Ciencia y Valores en Género, Valores y Sociedad en proceso editorial. OEI. (2002)

GUZMÁN, Laura. La paz y los derechos humanos en las vidas de las mujeres: Rompiendo silencios, abriendo nuevos caminos. San José: Instituto Interamericano de Derechos Humanos. (1994).

GUZMÁN, Laura. Repensando la familia y la violencia desde los derechos humanos de las mujeres. en Género, Valores y Sociedad en proceso editorial. OEI. (2002)

Lagarde, M. (2001) Claves feministas para la negociación en el amor. Managua: Puntos de Encuentro.

LÓPEZ Bombino, L. Por una nueva Etica. Ciudad de La Habana, Cuba. (en proceso editorial) Ciudad de La Habana, Felix Varela, 2002

PÉREZ, Eulalia. “¿El poder de una ilusión?: Ciencia Género y feminismo.” En Feminismos: del pasado al presente. España, Universidad de Salamanca. (2000).

PÉREZ Sedeño E. Las Mujeres en el Sistema de Ciencia y Tecnología, Madrid, Cuadernos de Iberoamérica OEI, (2001)

RUBIO Herráez Esther. Nuevos Horizontes de la Educación Sexista en Barral María José y Magallón Carmen editoras Interacciones ciencia y género. Barcelona: Icaria. (2000) VILLOTA de, Paloma. (Ed.) Globalización y Género. Madrid. Síntesis, 1999 